\title{
Considerações sobre a relação de causalidade na conexão de orações: da tradição à descrição
}

Fabrício da Silva Amorim*

Resumo: Através da análise de gramáticas tradicionais e descritivas, este artigo apresenta diferentes abordagens acerca da noção de causalidade estabelecida no nível interclausal. As análises evidenciam que o assunto em questão é geralmente abordado de maneira confusa pelas gramáticas de orientação tradicional. Entre as gramáticas descritivas consultadas, apenas em Neves (2000) é possível encontrar um tratamento mais acurado sobre o assunto. Apresenta-se, ainda, a proposta de Sweetser (1991), que, sob uma perspectiva semântico-pragmática, caracteriza a relação de causalidade em termos de domínios cognitivos.

Palavras-chave: relação de causalidade; gramáticas; domínios de causalidade.

Abstract: Through the analysis of traditional and descriptive grammars, this paper presents different approaches to the notion of causality at the inter-clausal established level. The analysis shows that traditional grammars commonly approach the subject in question in a confused way. Among the descriptive grammars analyzed, only in Neves (2000) one can find a more accurate argument about it. The proposal of Sweetser (1991) is also presented, according to which, from a semantic-pragmatic perspective, the relation of causality is described in terms of cognitive domains.

Keywords: relation of causality; grammars; domains of causality.

\section{Apresentação}

Este artigo, de caráter descritivo, visa a analisar como gramáticas baseadas em diferentes perspectivas têm abordado a relação de causalidade implementada no nível interclausal. Para tanto, toma como amostra de análise cinco gramáticas tradicionais Bechara (2009), Cunha e Cintra (2007), Nicola e Infante (2002), Terra (2002) e Savioli (2002) - e quatro gramáticas descritivas: Castilho (2010), Neves (2000), Perini (2006) e Perini (2010). Das gramáticas tradicionais analisadas, Nicola e Infante (2002), Terra (2002) e Savioli (2002) são aqui tratadas como gramáticas didático-tradicionais, na medida em que, além de se basearem na perspectiva tradicional, apresentam caráter didático por terem seu uso notadamente recomendado para os Ensinos Fundamental e Médio. Conforme apontam Dias e Bezerra (2006), a produção gramatical descritiva

\footnotetext{
* Doutorando em Estudos Linguísticos pela Universidade Estadual Paulista "Júlio de Mesquita Filho" UNESP/IBILCE.
} 
sobre o português, no final do século XX e início do século XXI, está fundamentada em diferentes teorias da linguística moderna. Assim, vale destacar que Perini (2006) e Perini (2010) se inserem em um modelo formal, enquanto que Castilho (2010) e Neves (2000) se pautam por uma visão funcionalista da linguagem.

Além de cotejar diferentes abordagens sobre a relação de causalidade a partir de gramáticas, este artigo apresenta a proposta de Sweetser (1991), que, assentada numa visão funcionalista, analisa a causalidade em termos de domínios cognitivopragmáticos.

Na seção a seguir, descreve-se, em linhas gerais, a relação de causalidade no nível interclausal. Na seção 3, a visão das gramáticas tradicionais e didático-tradicionais é analisada, de modo a evidenciar a insuficiência e, por vezes, a incoerência, dos seus critérios no trato com a relação de causalidade. A seção 4 ocupa-se da análise da visão das gramáticas descritivas, que, como se verá, em sua maioria, não dão conta de uma descrição mais pormenorizada das nuanças da causalidade. Na seção 5, apresenta-se a proposta de Sweetser (1991), apontada, junto com Neves (2000), como um modelo que tem sido bastante adotado nas investigações sobre as construções causais do português (Cf. AMORIM, 2012; CANDIDO, 2009; PAIVA; BRAGA, 2010, por exemplo). Por fim, apresentam-se as Considerações Finais.

\section{A relação de causalidade}

Linguisticamente, a relação de causalidade pode se manifestar através do ato de explicar ou através do ato de consecutar (PAIVA, 1991, p.08). No ato de explicar, o falante apresenta um fato X como origem ou motivação para um fato Y. No segundo caso, um fato é apresentado como consequência de outro. Na gramática tradicional, o primeiro ato corresponde às orações denominadas coordenadas explicativas e subordinadas adverbiais causais; o segundo, às coordenadas conclusivas e subordinadas consecutivas. Apesar de se reconhecer que há causalidade nos enunciados que configuram a consecução, será aqui discutida apenas a relação de causalidade manifestada através do ato de explicar. Assim, neste artigo, a noção de relação de causalidade no nível interclausal relaciona-se às tradicionalmente chamadas orações coordenadas explicativas e subordinadas adverbiais causais. 
A relação de causalidade não se estrutura apenas no plano referencial, isto é, um fato $\mathrm{X}$ pode representar a causa de um fato $\mathrm{Y}$, sem que $\mathrm{X}$ e $\mathrm{Y}$ estabeleçam uma relação causal observável no mundo real. Por exemplo, na argumentação pela causa (PLANTIN, 1990 apud PAIVA, 1991, p. 12), um falante estabelece uma relação causal entre A e B para justificar C (uma crença ou decisão, por exemplo, apresentada sob a forma de conclusão). Comparem-se os enunciados a seguir:

(1) João sente dores constantes no corpo porque sofreu um acidente.

(2) João estuda pouco porque sempre o vejo em festas.

Na primeira sentença, a cláusula "porque sofreu um acidente" codifica um fato que pode ser considerado causa real das dores sentidas por João. Há um consenso, estabelecido no discurso e pautado em valores sócio-históricos, que licenciam o estabelecimento da relação causa-efeito entre os fatos "sofrer acidente" e "sentir dores". A esse respeito, Ducrot (1983 apud PAIVA, 1991, p. 09) afirma que uma relação semântica entre A e B é garantida por um topos, definido como um princípio argumentativo do senso comum. Nesse sentido, uma conexão causal, por exemplo, pode ser estabelecida com base em relações semânticas e pragmáticas reconhecidas e aceitas anteriormente ao ato de enunciação. Na segunda sentença, a cláusula "porque sempre o vejo em festas" é apresentada como "causa" para o fato de que João estuda pouco. Notese que, nesse caso, não há a apresentação de uma causa real, mas uma tentativa de legitimar uma conclusão C, a saber, "Vejo João sempre em festas, portanto ele estuda pouco". Assim, a cláusula "porque sempre o vejo em festas" desempenha uma função argumentativa, já que conduz à conclusão C. Observa-se, portanto, que a noção de causa pode ser tomada em sentido estrito, quando se relaciona a outras noções como as de condição, tempo e agentividade ${ }^{1}$, ou em sentido amplo, quando se cruza com noções como as de razão, explicação, justificativa e argumento. (PAIVA, 1991, p. 13).

\footnotetext{
${ }^{1}$ Paiva (1991, p. 14-6) reconhece que, em muitos casos, as noções de condição, tempo e agentividade estão diretamente relacionadas à noção de causa estrita. Entretanto, salienta que as fórmulas "Se tenho A, tenho B" (condição), "A antecede B" (tempo) e "A intencionalmente produz B" (agentividade) podem não ser aplicáveis a todos os casos de causa estrita.
} 
Há, ainda, cláusulas causais que representam "justificações para atos de fala" (PAIVA, 1991, p. 19). Nesse caso, A representa um ato de fala e B, uma justificativa para a sua realização, como se vê em

(3) Vá embora, João, porque já é muito tarde.

em que o ato de fala ordem tem como justificativa o fato de "já ser muito tarde".

Em resumo, pode-se afirmar que a relação de causalidade, em se tratando da conexão de orações, pode ser evidenciada ou explorada (PAIVA, 1991, p. 19). O falante evidencia o elo de causalidade ao apresentar uma causa para um evento, estado ou um processo codificado na cláusula efeito. Esse elo é explorado quando o falante justifica/explica um ato de fala ou uma atitude expressa numa situação discursiva específica. Estudar a relação de causalidade requer, portanto, o reconhecimento de que a sua manifestação não é semanticamente estável, na medida em que existem relações causais mais ou menos estritas, o que é determinado pelo contexto pragmático em que emergem. Conforme se verá a seguir, nem sempre as gramáticas, sejam tradicionais, sejam descritivas, abordam, com clareza e pertinência, a manifestação dessa relação semântica tão variável no nível interclausal.

\section{A conexão causal em gramáticas de orientação tradicional}

Nas gramáticas tradicionais, a conexão causal é tratada no estudo das conjunções e do período composto. Em Terra (2002), Savioli (2002) (gramáticas didáticotradicionais) e Cunha e Cintra (2007), elencam-se conjunções que, nessa perspectiva, teriam se especializado, de um lado, em marcar explicação e, de outro, causa. Dessa maneira, são classificadas em coordenativas explicativas (porque, que, porquanto etc.) e subordinativas causais (porque, como, já que). Embora apresentem uma mesma conjunção como exemplo de coordenativa explicativa e subordinativa causal, como ocorre com o porque, nenhum desses gramáticos esclarece a diferença das noções causa e explicação. Implícita ou explicitamente, advogam a ideia de que a relação de causalidade tem sua origem na conjunção, e não no contexto sentencial em que se insere. A essa respeito, entre as gramáticas didático-tradicionais consultadas, apenas 
Nicola e Infante (2002) chamam a atenção para o fato de que "é o valor das orações que se transfere às conjunções, e não o inverso" (NICOLA; INFANTE, 2002, p.303).

Bechara (2009) faz menção à relação de causalidade apenas na seção em que trata das conjunções. Ao apresentar a lista das principais conjunções e locuções conjuntivas que marcam relações circunstanciais, Bechara considera causais as que exprimem "a causa, o motivo, a razão do pensamento da oração principal” (BECHARA, 2009, p. 326). Todavia, não há nenhuma consideração que leve à compreensão do que o autor entende por "causa", "motivo" ou "razão".

Conforme se mencionou na seção anterior, na perspectiva da gramática tradicional, a relação de causalidade é codificada pelas chamadas orações coordenadas explicativas e subordinativas adverbiais causais. Assim, a mesma distinção entre explicação e causa está presente na classificação dessas orações. No entanto, assim como no capítulo dedicado às conjunções, não se apresentam os critérios que diferenciam tais noções. Cunha e Cintra (2007) afirmam que uma oração é coordenada explicativa, "se a conjunção é explicativa" (CUNHA; CINTRA, 2007, p. 611); mas, "se a conjunção é subordinativa causal", é subordinada adverbial causal (CUNHA; CINTRA, 2007, p. 619). Note-se que, nesse caso, está presente o pressuposto de que é a conjunção a responsável pelo estabelecimento da relação causal, e não o contexto sentencial. Observem-se, abaixo, como as gramáticas didático-tradicionais consultadas definem as orações que estabelecem entre si uma conexão causal:

QUADRO 01: Definição de orações explicativas/causais, segundo gramáticas didático-tradicionais

\begin{tabular}{c|l|l} 
Gramática & \multicolumn{1}{|c|}{$\begin{array}{c}\text { Oração coordenada } \\
\text { explicativa }\end{array}$} & \multicolumn{1}{|c}{$\begin{array}{c}\text { Oração subordinada } \\
\text { adverbial causal }\end{array}$} \\
\hline Nicola e Infante (2002) & $\begin{array}{l}\text { Exprime o motivo, a } \\
\text { justificativa de se ter feito a } \\
\text { declaração anterior. (p. } \\
303)\end{array}$ & $\begin{array}{l}\text { Exprime a causa, o motivo } \\
\text { do que se declara na oração } \\
\text { principal. Causa pode ser } \\
\text { definida como aquilo ou } \\
\text { aquele que determina um } \\
\text { acontecimento. (p. 335) }\end{array}$ \\
\hline Terra (2002) & $\begin{array}{l}\text { Exprime ideia de } \\
\text { explicação, justificação, } \\
\text { confirmação. (p. 268) }\end{array}$ & $\begin{array}{l}\text { Exprime uma circunstância } \\
\text { de causa, aqui entendida } \\
\text { como motivo, isto é, aquilo } \\
\text { que determina ou provoca } \\
\text { um acontecimento. (p. 289) }\end{array}$ \\
\hline Savioli (2002) & Aquela que estabelece uma & \begin{tabular}{l} 
Aquela que indica a causa \\
\hline
\end{tabular}
\end{tabular}


relação de explicação. Explicação, aqui, deve ser entendida como confirmação do que se disse na oração anterior. (p. 98, grifos do autor) provocada do processo expresso pelo verbo da oração principal. (p. 78)

A observação do quadro acima permite afirmar que, nessas gramáticas, o tratamento dado à definição da relação de causalidade é confuso e equivocado. Nicola e Infante (2002), por exemplo, assumem que tanto na coordenada explicativa quanto na subordinativa causal há o "motivo" do que se expressa na declaração anterior. Não estabelecem, portanto, nenhuma diferença entre causa e explicação, embora, contraditoriamente, coloquem essas "orações de motivo" em categorias diferentes. Outro termo que chama a atenção, nas definições apresentadas, é "confirmação". Sobretudo em Savioli (2002), explicação reduz-se à confirmação: a fórmula "X porque $\mathrm{Y}=\mathrm{Y}$ confirma X” parece bastante equivocada. O surpreendente é que, à página 100 , Savioli apresenta o seguinte enunciado:

(4) "Deixa em paz meu coração/que ele é um pote até aqui de mágoa" (Chico Buarque)

em que o segmento em negrito - que, na realidade, representa uma justificativa para o ato de fala injuntivo (ordem/pedido) realizado na primeira oração - é classificado como oração coordenada explicativa. Fica claro, portanto, que não é possível afirmar que a oração destacada em (4) representa uma "confirmação do que se disse na oração anterior" (SAVIOLI, 2002, p. 98).

Apesar de não ter havido nas gramáticas consultadas a explicitação dos critérios utilizados para diferenciar explicação e causa, é possível inferir que seus autores parecem se basear em aspectos de ordem sintática e prosódica (Cf. PAIVA, 1991, p. 18). Nesse sentido, sintaticamente, causas estão para subordinação, enquanto que explicações estão para coordenação. Prosodicamente, a pausa que marca a separação das orações causais é menos acentuada da que separa as explicativas. Em todas as gramáticas examinadas, observa-se que os exemplos referentes às orações explicativas 
apresentam vírgula antes da conjunção; ao contrário, nos exemplos das orações causais, não se identifica a separação entre as orações. Vejam-se os enunciados a seguir, ambos retirados de Savioli (2002):

(5) A sessão foi suspensa porque faltou energia elétrica (SAVIOLI, 2002, p. 78)

(6) Deve ter chovido, pois o chão está molhado. (SAVIOLI, 2002, p.98)

As orações em destaque são apresentadas, respectivamente, como exemplo de oração subordinada causal e oração coordenada explicativa. Conforme assinalado, do ponto de vista semântico, o autor não estabelece uma distinção pertinente entre os dois tipos de oração. A partir da observação dos exemplos acima, é possível concluir que a distinção entre explicação e causa, nesse caso, é estabelecida com base no aspecto sintático e prosódico, de modo que a marcação formal da pausa (vírgula), como é o caso de (6), é responsável por explicitar uma relação de coordenação entre as orações, atribuindo o caráter de explicação à relação semântica estabelecida entre elas. Esses, no entanto, são critérios questionáveis e/ou insuficientes para diferenciar estruturas que codificam causalidade (CARVALHO, 2006; CUNHA, 2001; NEVES, 2001).

\section{A conexão causal em gramáticas de orientação linguística}

Para a discussão sobre o tratamento dado à conexão causal pelas gramáticas descritivas, foram consultados Perini (2006), Perini (2010), Castilho (2010) e Neves (2000). Em Perini (2006) e Perini (2010), nada se diz a respeito da relação de causalidade. Há apenas observações avulsas que permitem inferir que o autor atribui um caráter adverbial, nos termos tradicionais, à conexão causal. Nesses dois trabalhos, embora se apresentem os mecanismos de junção de cláusulas, não há uma classificação sistemática de orações, tampouco das conjunções responsáveis por sua conexão. Em Perini (2006), encontra-se a seguinte justificativa para ausência da subclassificação das conjunções: 


\begin{abstract}
já a subclassificação das conjunções adverbiais em "causais", "temporais" etc. tem base exclusivamente semântica e não caberia neste capítulo. E, de todo modo, a classificação tradicional é excessivamente pobre para exprimir toda a variedade de relações semânticas que as conjunções podem veicular. Por conseguinte, prefiro não subclassificar aqui as conjunções subordinativas... (PERINI, 2006, p. 139 - grifo acrescido)
\end{abstract}

A justificativa acima mostra, portanto, por que em Perini (2006) não se aborda a relação de causalidade: no trecho em destaque, o autor reconhece que não é tarefa fácil tratar da classificação das relações semânticas que emergem no nível interclausal e que são explicitadas através de conjunções, como acontece, por exemplo, com a conjunção porque, que costuma codificar diferentes nuanças da relação de causalidade. Ainda em relação ao trecho acima, é válido questionar a afirmação de que "a subclassificação das conjunções adverbiais em 'causais', 'temporais' etc. tem base exclusivamente semântica". Conforme mostram Neves (2000) e Sweetser (1991), uma relação semântica como a de causa é plurissignificativa devido a inferências pragmáticas. Dessa forma, a classificação das conjunções que codificam a causalidade - e as demais relações semânticas - não pode ser "exclusivamente semântica", como quer Perini (2006), já que, na língua em uso, esses conectores não se isentam da pressão pragmática que lhes acrescentam sentidos variados.

Em Perini (2010), conforme assinalado, também não há referência à relação de causalidade no capítulo em que o autor trata dos mecanismos de junção de orações. No entanto, ao se referir às conjunções - definidas como um tipo de conectivo cuja função é "transformar uma oração em SN, de modo que possa aparecer como sujeito, objeto etc. e receber os papéis temáticos correspondentes" (PERINI, 2010, p. 162) - o autor apresenta o exemplo

(7) O Rafael foi para Ouro Preto porque era aniversário dele. (PERINI, 2010, p. 162).

que permite entrever um tratamento da relação de causalidade não muito diferente da abordagem tradicional: segundo o autor, em (7), a oração introduzida por porque é um "sintagma adverbial com o papel de Causa". 
No capítulo dedicado ao estudo do período composto (sentença complexa), Castilho (2010) faz referência à relação de causalidade. Ao tratar da combinação de cláusulas, o autor chama a atenção para o fato de que o estabelecimento de relações semânticas entre orações não depende de conjunções, fornecendo como exemplo a relação de causalidade, que pode ser expressa “(i) por um complemento interno à oração; (ii) por verbos do tipo causar, provocar; (iii) pela retomada mediante um anafórico, em função de complemento de causa..."(CASTILHO, 2010, p. 344). Castilho também reconhece que, na relação de causalidade, existe diferença entre explicação e causação, admitindo a classificação em oração coordenada explicativa, para o primeiro caso, e subordinada adverbial causal, para o segundo. Apresenta, então, os seguintes exemplos:

(8) A rua está molhada porque choveu.

(9) Choveu, porque a rua está molhada.

No primeiro caso, Castilho alega haver a causação, pois o conector porque liga dois conteúdos proposicionais, caracterizados, respectivamente, como efeito e causa. No segundo caso, o segmento "porque a rua está molhada" não pode ser apontado como causa do fenômeno "chover". Trata-se, portanto, de uma explicação possível (CASTILHO, 2010, p. 348). É possível afirmar, então, que o autor considera adverbiais causais apenas as orações que expressam causa estrita, ficando a classificação em coordenadas explicativas para as que expressam relação causal em sentido mais amplo. Seu tratamento, portanto, é bastante semelhante ao que se vê na perspectiva tradicional.

Ao abordar especificamente as orações adverbiais causais, Castilho (2010, p. 374 ) cita as principais conjunções que as introduzem, a saber, porque, desde que, como, que, já que, destacando ser a primeira a conjunção prototípica da causalidade no português brasileiro. $\mathrm{Na}$ mesma seção em que trata das orações adverbiais causais, baseando-se em Dias de Moraes (1987), Castilho faz referência ao uso do porque depois de imperativo e apresenta o seguinte exemplo:

(10) "não me chame de madame H...porque madame aqui no Brasil (...) casa de madame...como se fosse uma casa de coleteira..." (CASTILHO, 2010, p. 374) 
O autor reconhece haver em (10), no segmento introduzido pela conjunção porque, uma causa explícita. Entretanto, esse mesmo segmento pode ser visto como uma justificação ao ato de fala ordem presente na primeira oração. Por admitir a diferença entre explicação e causação, esse não seria um exemplo mais adequado à explicação, devendo, portanto, ser apresentado no rol das coordenadas explicativas, e não das subordinadas causais?

Neves (2000) apresenta um tratamento mais pormenorizado acerca da relação de causalidade. Após elencar os itens conjuncionais responsáveis pela conexão causal, descreve a relação de causalidade tomada em dois sentidos mais gerais, a saber, o estrito e o amplo. A causa estrita refere-se à relação causa-consequência, ou causa-efeito, entre dois eventos e pressupõe uma anterioridade temporal da causa em relação ao efeito. Porém, nos casos em que a "causa efetiva", nos termos de Neves (2000, p. 804), é estabelecida entre estados de coisas não dinâmicos, não há a implicação da temporalidade. A causa ampla, por sua vez, pode se manifestar a) no domínio epistêmico, em que a relação causal se pauta em um conhecimento, julgamento ou crença do falante, tradicionalmente denominada "causa formal" e b) nas relações entre um ato de fala ${ }^{2}$ e a expressão do que motivou este ato. A relação causal do tipo b) é "uma relação mais frouxa do que uma relação verdadeiramente causal (em qualquer de suas subespécies, como motivo, razão, justificativa etc.), próximo de uma explicação" (NEVES, 2000, p. 806, grifos da autora). Em resumo, a proposta de Neves prevê que as relações causais podem ser codificadas entre predicações (estados de coisas); entre proposições (fatos possíveis) ou entre enunciados (atos de fala). Poder-se-ia postular um continuum a partir dessa proposta, levando em conta que a relação causal, como uma categoria cognitiva, apresenta nuances que podem ser postas em termos de uma escala crescente de abstratização. Assim:

CAUSA EFETIVA (ENTRE PREDICAÇÕES) > CAUSA FORMAL (ENTRE PROPOSIÇÕES) $>$ EXPLICAÇÃO (ENTRE ENUNCIADOS)

\footnotetext{
${ }^{2}$ Neves (2000, p. 805) considera os seguintes atos de fala: declarativo, interrogativo e injuntivo
} (deôntico ou imperativo). 
Tendo em vista os aspectos cotejados nesta seção, nota-se que a relação de causalidade é pouco explorada, tanto na perspectiva tradicional quanto nos trabalhos de orientação linguística. Quando se trata, em ambas as perspectivas, da conexão causal, a proposta de distinção das noções de causa e explicação, geralmente, carece de clareza, não dispondo ainda de critérios mais precisos que possam demarcar suas fronteiras. Vale ressalvar, entretanto, que Neves (2000) apresenta uma análise bastante profícua à compreensão da configuração da relação causal entre cláusulas no português.

Outro trabalho que tem destaque no estudo das conjunções e de articulação de cláusulas é o de Sweetser (1991). Veja-se, abaixo, como a autora analisa a relação de causalidade.

\section{O Tratamento de Sweetser (1991)}

Uma mesma relação semântica, como a de causa, pode apresentar valores ambíguos e diversos, que são pragmaticamente determinados. Nesse sentido, as conjunções, por exemplo, por explicitarem uma relação semântica estabelecida na conexão de orações, podem ser polissêmicas, ou polifuncioanis, como destaca Castilho (2010, p. 345). Sweetser (1991, p. 76-86) examina os diferentes valores causais da conjunção inglesa "because", propondo que a relação de causalidade pode se manifestar em três domínios distintos - referencial, epistêmico e dos atos de fala.

Para explicar cada manifestação, a autora fornece os seguintes exemplos:

(11) John came back because he loved her.

(12) John loved her, because he came back.

(13) What are you doing tonight, because there's a good movie on. ${ }^{3}$

No primeiro caso, uma causa real conecta as duas orações: o amor que John sentia por ela é apontado como causa de seu retorno. No caso seguinte, a inversão das orações provocou uma alteração na relação causal estabelecida, visto que, factual e

\footnotetext{
${ }^{3}$ João voltou porque a amava/ João a amava, porque voltou/O que você vai fazer esta noite, porque está passando um filme legal. (Tradução do autor deste artigo)
} 
diretamente, não é possível dizer que o retorno de John foi a causa do amor que ele sentia por ela. Nesse caso, a relação efeito ("John loved her”)/causa ("because he came back") é entendida em termos de conhecimentos outros que extrapolam o nível referencial: há, na realidade, uma conclusão baseada em inferências do locutor ("João voltou, portanto ele a amava."). Em (13), se considerada referencialmente, a relação causal estabelecida não teria coerência: como a afirmação de que "um filme legal está sendo exibido" pode ser causa da pergunta “o que você vai fazer nesta noite?"? Na realidade, a oração introduzida pela conjunção causal "because" representa uma justificativa para o ato de fala codificado na primeira oração: pergunto o que você vai fazer esta noite, porque quero sugerir que vejamos um filme.

Vejam-se mais exemplos abaixo:

(14) Antônio não concluiu o trabalho porque foi impedido pelos colegas.

(15) O trabalho foi concluído, porque Antônio está tranquilo.

(16) Conclua o trabalho, Antônio, porque terá de entregá-lo amanhã.

Em (14), a não conclusão do trabalho se deveu à ação de impedimento efetuada pelos colegas de Antônio. Nesse caso, uma causa real é assinalada, apresentando, inclusive, o traço de agentividade (a referida ação foi praticada pelos colegas de Antônio - causa), caracterizador de uma relação causal prototípica. No segundo caso, o fato de Antônio estar tranquilo não pode ser causa real da conclusão do trabalho: a relação de causalidade, nesse caso, é estabelecida com base na inferência de que a tranquilidade de Antônio sinaliza que ele concluiu o trabalho. Para Anscombre (1993 apud PAIVA, 1991), a cláusula "porque Antônio está tranquilo" representa uma causa alegada, "a causa criada pelo falante no ato da enunciação, estabelecida a partir do seu julgamento acerca da relação entre os fatos" (PAIVA, 1991, p. 14). Em (16), a relação causal é estabelecida a partir da seguinte interpretação: estou pedindo/ordenando que você, Antônio, conclua o trabalho e justifico esse pedido/ordem salientando que o prazo para entregá-lo está se esgotando. Assim, a conjunção causal em (14) está no domínio referencial; em (15), no domínio epistêmico e, em (16), no domínio dos atos de fala: 
Causal conjunction is in the speech-act domain, then, indicates causal explanation of a speech act being performed, while in the epistemic domain a causal conjunction will mark the cause of a belief or a conclusion, and in the content domain it will mark a "real-world" causality of an event. (SWEETSER, 1991, p. 81)

Há casos, entretanto, em que a determinação desses domínios se torna ambígua, como se observa no enunciado a seguir:

(17) Antônio não concluiu o trabalho porque decidiu viajar.

em que duas interpretações são possíveis. Pode-se considerar, de imediato, que a decisão de viajar, ou seja, a redução de tempo disponível para a conclusão do trabalho, é causa real do fato de Antônio não o ter concluído. Numa outra leitura, a ideia de redução de tempo para a conclusão do trabalho pode não ser codificada de imediato. Com isso, a "decisão de viajar", em si, não pode ser considerada causa efetiva para a não conclusão do trabalho, a menos que o locutor assuma essa relação a partir de uma conclusão pessoal. Dessa forma, a relação causal presente em (17) pode ser flagrada no domínio referencial ou no domínio epistêmico. Sweetser (1991, p. 78) assinala que a escolha da interpretação correta da relação de causalidade depende do contexto pragmático em que a sentença se insere. Em outras palavras, "a noção de causalidade só pode ser investigada com relação à organização do discurso, aí incluídas todas as questões ligadas à distribuição de informação e à orientação argumentativa" (NEVES, 2000, p. 808).

A proposta descrita acima se assemelha bastante ao tratamento apresentado por Neves (2000). No entanto, a partir dos exemplos por ela apresentados, pode-se concluir que Sweetser (1991) inclui no domínio dos atos de fala apenas os casos em que o ato de fala realizado no segmento efeito é injuntivo (pedido, ordem, conselho) ou interrogativo. Neves (2000), além de reconhecer esses atos, trata mais explicitamente dos atos de fala declarativos. No enunciado a seguir, por exemplo, o segmento causal

\footnotetext{
${ }^{4}$ Uma conjunção causal no domínio dos atos de fala indica, portanto, uma explicação do ato de fala sendo realizado, enquanto no domínio epistêmico uma conjunção causal marcará a causa de uma crença ou conclusão, e, no domínio referencial, expressará a causa, observável no mundo real, de um evento. (Tradução do autor deste artigo)
} 
justifica um ato de fala declarativo, uma vez que ao afirmar "Prometo que lhe contarei o segredo", o locutor não está apenas dizendo algo, mas realizando algo, a saber, fazendo uma promessa:

(18) Prometo que lhe contarei o segredo, porque confio em você.

Dado o exposto, além dos atos injuntivos e interrogativos, é possível reconhecer, conforme o faz Neves (2000), que

as frases declarativas podem encerrar atos de fala. Quando o fazem, são chamadas de Performativas, segundo a proposta de Austin (1962, 1970). As asserções propriamente ditas caracterizam as chamadas frases Constativas. Assim, quando uma frase é realizada não apenas para dizer algo, mas para fazer alguma coisa, dizemos que é performativa (CABRAL, 2010, p. 25).

\section{Considerações Finais}

Neste artigo, foram caracterizadas diferentes abordagens sobre a relação de causalidade estabelecida no nível interclausal. A análise evidenciou que, nas gramáticas de orientação tradicional, a relação de causalidade é vista a partir da dicotomia explicação/causa. Não há, entretanto, a explicitação de critérios para a distinção entre essas noções. No caso das gramáticas descritivas, em Perini (2006) e Perini (2010) pouca ou nenhuma menção é feita à relação de causalidade. Em Castilho (2010), embora haja profícuas observações acerca do estabelecimento de relações semânticas entre orações, também não é possível encontrar um refinamento quanto à definição de causa e explicação.

As propostas de Neves (2000) e Sweetser (1991), dentro do universo de investigação deste trabalho, apresentaram-se como as mais adequadas quanto à noção de causalidade: ambas as autoras, assentadas numa visão funcionalista da linguagem, assumem que a relação de causalidade pode ser investigada a partir de um continuum. Assim, o rompimento com a visão dicotômica, tão recorrente nas gramáticas de orientação tradicional, permite mostrar que, na realidade, a relação de causalidade se dispõe numa escala crescente de abstratização, havendo, nesse sentido, noções de causa 
mais concretas, quando, por exemplo, a causalidade se estabelece entre eventos do mundo real, e noções de causa mais alargadas, quando o falante explora o elo de causalidade com finalidades diversas, como, por exemplo, fornecer uma justificativa para um ato de fala. Essas parecem alternativas seguras para o exame de construções causais (Cf. AMORIM, 2012; CANDIDO, 2009; PAIVA; BRAGA, 2010), na medida em que não se atêm a categorias estanques, mas reconhece o caráter fluido das relações semânticas e, por conseguinte, da língua.

\section{Referências Bibliográficas}

AMORIM, Fabrício da Silva. Construções causais com por causa que: um caso de gramaticalização. 2012. 118 f. Dissertação (Mestrado em Letras: Língua e Cultura). Instituto de Letras, Universidade Federal da Bahia, Salvador, 2012.

BECHARA, Evanildo. Moderna gramática portuguesa. $37^{\circ}$ ed. Rio de Janeiro: Lucerna, 2009.

CABRAL, Ana Lúcia Tinoco. A força das palavras: dizer e argumentar. São Paulo: Contexto, 2010.

CANDIDO, Fernanda Maria. Os diferentes padrões das construções com pois. 2009. 131 f. Dissertação (Mestrado em Linguística e Língua Portuguesa). Universidade estadual paulista "Júlio de Mesquita Filho", Araraquara, 2009.

CASTILHO, Ataliba T. de. Gramática do português brasileiro. São Paulo: Contexto, 2010.

CARVALHO, Cristina dos Santos. A conexão de causalidade na fala culta de Salvador. Revista de Letras, v. 1, 2006. p. 1-25.

CUNHA, Celso; CINTRA, Lindley. Nova Gramática do Português contemporâneo. $4^{\text {a }}$ ed. Rio de Janeiro: Lexikon, 2007.

CUNHA, Antônio Sérgio Cavalcante da. O comportamento sintático das conjunções causais/explicativas. SOLETRAS (UERJ), São Gonçalo, v. 02, 2001. p. 20-37.

NEVES, Maria Helena de Moura.Gramática de usos do português. São Paulo: Unesp, 2000. p. 801-829.

A gramaticalização e a organização dos enunciados. SCRIPTA, Belo Horizonte, v. 5, n. 9, 2 o semestre, 2001. p. 174-182. 
DIAS, Luiz Francisco; BEZERRA, Maria Auxiliadora. Gramática e Dicionário. In: GUIMARÃES, E.; ZOPPI-FONTANA, M. (Orgs.). Introdução às Ciências da Linguagem - A palavra e a frase. Pontes: Campinas, 2006. p. 11-37.

NICOLA, José de; ULISSES, Infante. Gramática contemporânea da língua

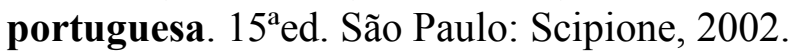

PAIVA, Maria da Conceição de. Ordenação de cláusulas causais: forma e função. 1991. Tese (Doutorado em Linguística). 238 f. Faculdade de Letras, Universidade Federal do Rio de Janeiro, Rio de Janeiro, 1991.

; BRAGA, Maria Luiza. Cláusulas causais introduzidas por porque: da sintaxe ao discurso. In: MOLLICA, Maria Cecília. (Org.). Usos da linguagem e sua relação com a mente humana. Rio de Janeiro: Editora Tempo Brasileiro, 2010, v. 1, p. 55-71.

PERINI, Mário A. Gramática do português brasileiro. São Paulo: Parábola, 2010. Gramática descritiva do português. $4^{\circ}$ ed. São Paulo: Ática, 2006.

SAVIOLI, Francisco Platão. Gramática em 44 lições. 32ªed. São Paulo: Ática, 2002.

SWEETSER, Eve. From etymology to pragmatics. Cambridge: Cambridge University, 1991. p. 23-48.

TERRA, Ernani. Curso prático de gramática. 4ªed. São Paulo: Scipione, 2002.

Artigo recebido em: 31.03.2012

Artigo aprovado em: 07.06.2012 